\title{
Does South African research output promote \\ innovation?
}

AUTHORS:

Roula Inglesi-Lotz' ${ }^{1}$ iD

Anastassios Pouris ${ }^{2}$

\section{AFFILIATIONS:}

'Department of Economics, University of Pretoria, Pretoria, South Africa

2Institute for Technological Innovation, University of Pretoria, Pretoria, South Africa

\section{CORRESPONDENCE TO:}

Roula Inglesi-Lotz

\section{EMAIL:}

roula.inglesi-lotz@up.ac.za

\section{KEYWORDS:}

R\&D; publications; patents; technology

\section{HOW TO CITE:}

Inglesi-Lotz R, Pouris A. Does South African research output promote innovation? S Afr J Sci. 2018;114(9/10), Art. \#a0286, 3 pages. https://doi. org/10.17159/sajs.2018/a0286

\section{PUBLISHED:}

11 September 2018
Research and development (R\&D) activities that lead to innovation can contribute highly to a country's economic growth and development. However, research output can be expressed in different forms, such as research publications and patents. Patents are considered to be closer to implemented innovation than are research publications, but research publications improve human capital and propose innovative solutions that can lead to patenting activities. So although they are two different outcomes, publications and patents can work in synergy.

A recently published article entitled 'Patents vs publications and R\&D: Three sides of the same coin? Panel Smooth Transition Regression (PSTR) for OECD and BRICS countries'1 in the journal Applied Economics, identified the existence of research thresholds beyond which countries can move in the next stage and increase their number of patents. The concept tested was that a minimum number of publications (as a proxy to research capacity) should be reached before a country or a region can engage in patenting activities that will eventually promote higher innovation and consequently economic growth.

In that paper, we investigated the existence of thresholds in the OECD and the BRICS countries and found that the threshold of publications before patenting activity started was 11113 for the whole sample, 9038 for the OECD countries and 9945 for the BRICS countries.

The effect of the number of publications and $R \& D$ as variables of transition is opposite. Beyond the threshold, the number of publications increases the possibility of patenting for the two groups of countries. However, beyond the threshold of R\&D this variable decreases the probability of patenting. From these results and based on the optimal threshold, we conclude that patents in OECD and BRICS countries are positively influenced by the number of publications. ${ }^{1}$

Based on these thresholds, South Africa has not yet reached the relevant level of the estimated threshold even though the country's research publications (in all disciplines) have increased substantially over the recent decade (Figure 1). ${ }^{2}$

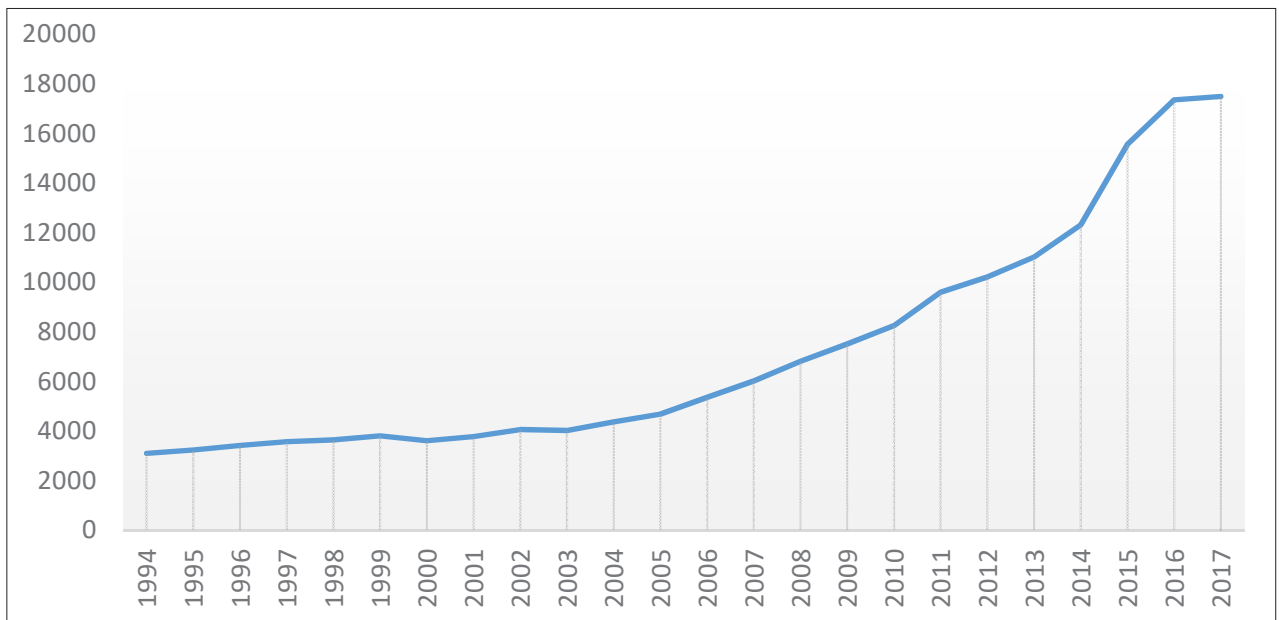

Source: Clarivate Analytics ${ }^{2}$

Figure 1: South African research publications in all disciplines, 1994-2017.

The question then arises as to why South Africa has not yet reached the threshold and whether the disciplines of the publications in the country play a role. Obviously, patents require particular skills that may not be available in a country because of policy preferences and directions. This Commentary provides evidence of the current distribution of the research publications of South Africa according to five major clusters of research. The article is also important for the setting of research priorities in the country.

\section{Empirical analysis}

Globally, countries with high innovation levels and improvements in technology have generally produced more research publications in disciplines of technology than other types of science. That is to say, those countries that drive technology research globally tend to enjoy higher levels of economic growth, living standards and development. $^{2}$ Figure 2 presents countries' shares of the world's total research in the discipline of technology, as a representation of their strength in technology research. 'Technology' as a discipline includes: Acoustics, Automation and Control Systems; Computer Sciences; Construction \& Building Technology; Energy \& Fuels; Engineering; Imaging Science \& Photographic Technology; Information Science \& Library Science; Instruments \& Instrumentation; Materials Science; Mechanics; Metallurgy \& Metallurgical Engineering; Microscopy; 
Nuclear Science \& Technology; Operations Research \& Management Science; Remote Sensing; Robotics; Science \& Technology Other Topics; Spectroscopy; Telecommunications; Transportation.

The distribution in Figure 2 is skewed, with China and the USA producing more than $40 \%$ of the total $(23.1 \%$ and $19.5 \%$, respectively) and all the other countries producing less than $5 \%$. Not surprisingly, developed countries such as the USA, Germany, France and Italy are in the top 10, but the BRICS countries are also well represented. China is in first place (with $23.1 \%$ ) and India in fifth place (with $4.6 \%$ ), while Russia is 15th with $1.7 \%$ and Brazil 16 th with $1.6 \%$ of the total share in world research in the Technology field. South Africa, however, does not follow the high research productivity of the rest of the emerging technologies, producing only $0.37 \%$ of the world's share of research publications in Technology.

But is South Africa lacking in research publications in only Technology? Table 1 shows the broader scientific disciplines in which South Africa has published research outputs for the period from 1995 to 2016. The information included is the number of publications produced with at least one South African author in each broad scientific field; the share of each discipline in the South African set of publications; the country's share of the world's publications in the particular field and South Africa's world ranking in each field.
South Africa is ranked 18th in the world in Social Sciences and Arts and Humanities; 33th in Life Sciences; 38th in Physical Sciences and 40th in Technology (out of 198 countries in the data set). It is important to note that different metrics could lead to different conclusions about the country's strengths and weaknesses. For example, proponents of arts and humanities or researchers with limited information may use the number of publications in order to provide additional support in the field. South Africa's ranking in the world is probably the most revealing one as it takes into account international preferences and emphases.

From Table 1, it can be seen that South Africa's research capacity varies among the different broad research disciplines. Looking only at the number of publications in each discipline, one can observe that, for example, the Arts and Humanities discipline publishes approximately one fourth of the papers of the Technology or Physical Sciences. That observation might mislead policy into promoting R\&D funding towards arts and humanities to increase their productivity. However, by evaluating the rankings, a better understanding of the world's research in this discipline is offered. A good example is the comparison between Social Sciences and Technology - at 31 thousand and 37 thousand papers, respectively - for which South Africa is ranked 18th in the former and 40th in the latter!

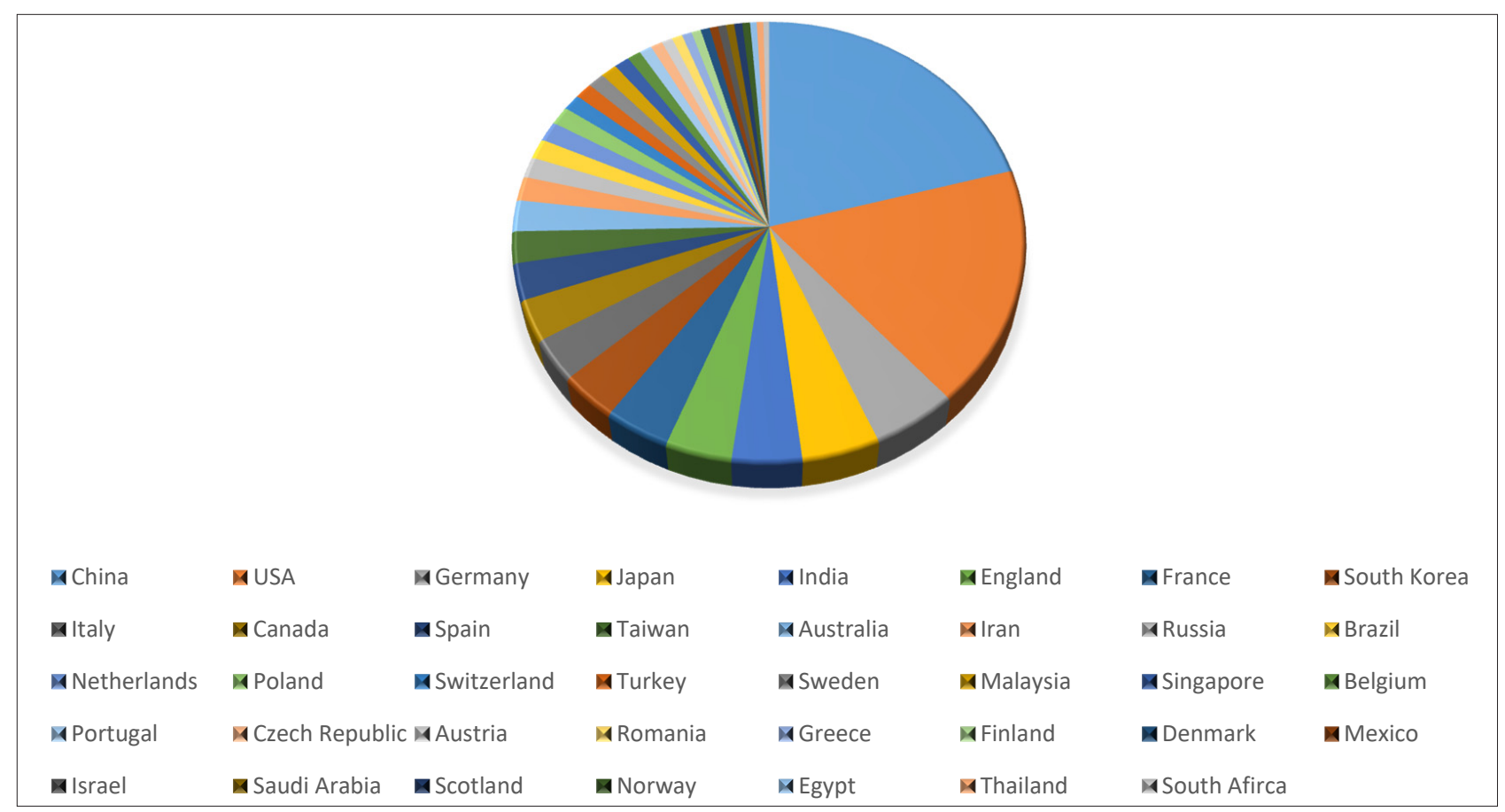

Source: Clarivate Analytics ${ }^{2}$

Figure 2: Research in the Technology field (country's share of the world's total, \%) in 2016.

Table 1: $\quad$ Research performance of South Africa per discipline, 1995-2016

\begin{tabular}{l|c|c|c|c}
\hline \hline \multicolumn{1}{|c|}{ Discipline } & Number of publications & Share of South Africa's total & $\begin{array}{c}\text { South Africa's share of the } \\
\text { world total }\end{array}$ & $\begin{array}{c}\text { South Africa's world ranking } \\
\text { (out of 198 countries) }\end{array}$ \\
\hline Social Sciences & 31651 & $13.9 \%$ & $0.80 \%$ & 18 \\
\hline Arts and Humanities & 8842 & $3.9 \%$ & $0.33 \%$ & 18 \\
\hline Life Sciences & 103441 & $45.4 \%$ & $0.63 \%$ & 33 \\
\hline Physical Sciences & 46119 & $20.2 \%$ & $0.50 \%$ & 38 \\
\hline Technology & 37847 & $16.6 \%$ & $0.37 \%$ & 40 \\
\hline
\end{tabular}

Source: Authors' calculations on data from $\mathrm{NACl}^{3}$ 


\section{Discussion}

This Commentary aims to provide a broad picture of the revealed priorities (priorities revealed by the volume of publications in particular research domains) in South Africa and how the choice of indicators may affect the relevant conclusions.

Table 1 shows that if the criterion was number of publications or share of the country's total number of publications, the verdict would have been that South Africa emphasises life sciences and neglects arts and humanities. If the criterion was South Africa's share of the world's publications, the results would have shown that South Africa makes the greatest contribution in the social sciences $(0.80 \%)$. Finally, if the criterion is South Africa's ranking in the world, the results would show that the country ranks 18th in the world in social sciences and humanities and 40th in the domain of technology. The reasoning behind these variations is that different scientific publications have different publication patterns that have to be remedied when priorities or comparisons among different countries are investigated. While further research is required, it will be interesting to investigate whether emphasis on different scientific disciplines/domains affects a country's capability to invent and innovate.
South Africa has promoted particularly the advancement of humanities and social sciences fields through the established of the National Institute for the Humanities and Social Sciences (NIHSS) in 2013. The Institute coordinates scholarship, research and ethical practice in these fields within and through the country's public universities. While the impact of the Institute cannot yet be estimated and quantified, the research performance in the fields is an interesting indication that the specific disciplines have grown. Policymakers may have to investigate such opportunities for the technology field too.

\section{References}

1. Inglesi-Lotz R, Hakimi A, Pouris A. Patents vs publications and R\&D: Three sides of the same coin? Panel Smooth Transition Regression (PSTR) for OECD and BRICS countries. Appl Econ. 2018;50(45):4912-4923. https:// doi.org/10.1080/00036846.2018.1468556

2. Clarivate Analytics. Web of Science database [database on the Internet]. No date [cited 2018 Aug 15]. Available from: https://clarivate.com/products/ web-of-science/databases/

3. National Advisory Council on Innovation (NACl). South African science, technology and innovation indicators report. Pretoria: NACl; 2017. Available from: http://www.naci.org.za/wp-content/uploads/2018/07/South_African_ Science_Technology_And_Innovation_Indicators_Report_2017.pdf 